\title{
Uma Análise Sistêmica dos Determinantes da Fragilidade Financeira Minskyana ${ }^{\dagger}$
}

\author{
- Thiago Fonseca Morello*
}

\begin{abstract}
Resumo
O objetivo do presente artigo é identificar os fundamentos, próprios à dimensão da atividade produtiva, da capacidade de uma empresa capitalista para financiar internamente suas operações. Adotando-se a concepção de Minsky, constrói-se um modelo computacional microeconômico. A emulação do lado real e do lado financeiro de uma economia, a partir de apenas um algoritmo comportamental, i.e., de apenas um tipo de agente, firmas, no caso, é a principal característica do modelo. Os resultados são: (i) é possível, a pena de um erro estatístico não superior a 5\%, classificar uma firma como hedge ou não-hedge, com base apenas no conhecimento da taxa de realização da produção, da proporção do valor do produto correspondente ao custo de produção e da sensibilidade do investimento à taxa de lucro esperada e; (ii) tal possibilidade sustenta-se dinamicamente.
\end{abstract}

\section{Palavras-chave}

Fragilidade Financeira, Ciclos Econômicos, Comportamento das unidades econômicas, Complexidade

\begin{abstract}
The goal of the following paper is to identify the foundations, circumscribed to the productive activities, of the inner financing capacity of a capitalist firm. By adopting Minsky's conception, a computational microeconomic model is proposed. The emulation of both the real and the financial side of an economy, from only one behavioral algorithm, i.e., only one type of agent, firms, is the main characteristic of the model.The results are: (i) is possible, incurring in a statistical error not bigger than $5 \%$, to classify a firm as hedge or not-hedge, from the knowledge of only the production realization rate, the ratio between unitary cost and price and the sensibility of investment to the expected profit and; (ii) such possibility is kept dynamically.
\end{abstract}

\section{Keywords}

Financial Fragility, Business Cycles, Economic Units' Behavior, Complexity

\section{JEL Codes}

E12, D21, C63.

- Agradeço aos professores Gilberto Tadeu Lima e Eleutério Prado, bem como aos demais membros do Complex (núcleo de Economia e Complexidade do Departamento de Economia da FEA-USP), pelas críticas e comentários feitos a versões anteriores do texto e, principalmente, pelo estímulo para levar à frente este estudo.

* Doutorando em Economia das Instituições e do Desenvolvimento pelo IPE/FEA-USP. E-mail: tfmrs@ yahoo.com.br. Membro do Nucleo de Economia Socioambiental da USP (NESA-USP). Endereço para contato: Av. Prof. Luciano Gualberto, 908 - Cidade Universitária - São Paulo - CEP: 05508-010.

(Recebido em agosto de 2008. Aceito para publicação em julho de 2010). 


\section{Introdução}

Da leitura de autores como Keynes (1936) e Minsky (1975 e 1982) é possível depreender uma teoria dos ciclos econômicos capitalistas inovadora e crítica da visão neoclássica. O nível de investimento produtivo é posto como gerador das transições de fase cíclicas, representando uma espécie de síntese das duas esferas de uma economia capitalista, a da produção (ou lado real) e a financeira.

Busca-se, no presente artigo, explorar as concepções Keynesiana e Minskyana sob uma perspectiva microeconômica, ou bottom-up, assim como em Gallegati et al (2003), Battiston et al (2007) e Russo et al (2004). Quanto a isso é preciso destacar uma ruptura com o reducionismo típico à microeconomia mainstream. Nos artigos citados, a análise não se restringe ao domínio da tomada individual de decisão, englobando, com ênfase, as interações entre as unidades tomadoras de decisão. O esclarecimento das maneiras pelas quais o comportamento individual apresenta-se não apenas como causa, mas também enquanto consequência dessas interações, é parte crucial do problema de pesquisa.

Em Gallegati et al (2003), é por meio da interação entre banco e firmas que o processo de contágio financeiro é desencadeado. Já em Battiston et al (2007), é a partir das interações entre firmas que ocupam posições diferenciadas na hierarquia de uma cadeia produtiva que a fragilidade financeira é transmitida. Em Russo et al (2004), tem-se por meta avançar na compreensão das razões pelas quais padrões de distribuição entre firmas do porte (ou tamanho) mensurado pela magnitude do capital acumulado logram emergir. Foca-se, para isso, nas relações estabelecidas entre firmas para transacionar produtos e nas relações estabelecidas entre firmas e banco para transacionar crédito.

No artigo ora introduzido, a troca de produtos entre firmas é posta como relação crucial para a compreensão do processo de geração da capacidade de financiamento interno. O grau de fragilidade financeira é tratado como uma variável de natureza interacional, da mesma maneira como em Gallegati et al (2003), Battiston et al (2007), Russo et al (2004) e Lima \& Freitas (2007). Há, porém, uma distinção meritória de assinalamento. Nesses quatro artigos são especificadas regras comportamentais que regem o funcionamento do "lado da oferta", i.e., a maneira pela qual o nível de produção das unidades é estabelecido. Já a demanda é reduzida a um processo estocástico que estabelece o preço corrente pelo qual será vendido cada um dos produtos. Não se tenta, portanto, relacionar o nível da demanda a quaisquer decisões tomadas pelas unidades cujas regras comportamentais são dadas pelo modelo. Essa assimetria, no que tange ao nível de detalhamento dos processos que geram oferta e demanda, não encontra paralelo no modelo aqui apresentado. 
O conjunto de empresas simulado gera tanto um vetor de produção como um vetor de demanda por produção, de modo que as vendas (e compras) resultam da compatibilização destes dois vetores, não existindo qualquer magnitude da demanda (ou da oferta) que não possa ser explicada a partir do algoritmo que rege o comportamento das unidades simuladas.

A centralidade da decisão acerca do investimento produtivo é um denominador comum a Gallegati et al (2003), Battiston et al (2007), Russo et al (2004), Meirelles \& Lima (2006), Taylor \& O'Connel (1985), Foley (1986), Foley (2003) e Fazzari et al (2008). De maneira equivalente, a decisão crucial para a dinâmica da economia hipotética, simulada no presente estudo, é a de quanto produzir ou de quanto investir na produção.

O "lado financeiro da economia" é, assim como em Battiston et al (2007), consideravelmente simplificado para incorporar apenas transferências não intermediadas entre firmas - o que em Battiston et al (2007) denomina-se trade credit. Essa redução pouco realista permite uma simplificação considerável do algoritmo computacional: as transações financeiras e as transações de produtos podem ser simuladas a partir do mesmo conjunto de unidades. A incorporação ao modelo de agentes que desempenhem o papel de bancos torna-se, pois, desnecessária, contrariamente ao que vale em Gallegati et al (2003), Battiston et al (2007), Russo et al (2004), Lima \& Freitas (2007) e Foley (1986).

O objetivo do presente artigo é identificar os fundamentos, circunscritos ao lado real da economia, da capacidade de uma empresa capitalista para financiar internamente suas operações. Esta capacidade pode ser classificada em três categorias, ou posturas, de acordo com a taxonomia proposta por Minsky (1982), reduzindo-se, com isso, a análise à identificação das razões pelas quais uma empresa é classificada em cada categoria.

Com exceção de Meirelles \& Lima (2004), não foi possível encontrar um estudo detalhado das causas últimas da transição entre as posturas minskyanas na literatura que invoca essa taxonomia. O presente artigo deve ser visto como uma tentativa de lançar luz sobre tal aspecto, aprofundando o entendimento do mecanismo pelo qual empresas capitalistas perdem ou ganham capacidade para financiar internamente suas operações.

Para levar a cabo a meta demarcada, formula-se um modelo computacional baseado em agentes (agent based model, na definição de Axelrod \& Tesfatsion: 2009), cuja estrutura de funcionamento é apresentada na seção a seguir. A construção deste instrumento analítico apoia-se nas contribuições de autores como Von Neumann e 
Wolfram (CASTI,1992 e WOLFRAM, 2002), fundadores da chamada ciência da complexidade. Trata-se de uma perspectiva crescentemente adotada na pesquisa em economia, como registram Lima \& Freitas (2007), cujo fundamento filosófico está assentado, segundo Foley (2003) e Prado (2006), na visão sistêmica.

Na terceira seção são identificadas, a partir de manipulações algébricas, três variáveis a partir das quais é possível propor princípios de transição entre posturas hedge e não-hedge. A verificação da validade desses princípios, com base nos resultados gerados pelo modelo, é empreendida na quarta seção do artigo. A última seção conclui o estudo.

\section{Apresentação do Modelo}

\subsection{Hipóteses Estruturais}

No modelo temos 36 firmas, cada uma delas responsável por gerar um produto específico, por meio de uma estrutura tecnológica de mesmo modo específica. Cada firma localiza-se em uma vizinhança de transação de produtos (a qual chamaremos simplesmente vizinhança) e em uma vizinhança de transação de certificados de dívida - no que segue eventualmente denominada vizinhança expandida. ${ }^{1}$ A figura abaixo mostra em que consiste cada uma delas, tomando a firma de número 4 como referência.

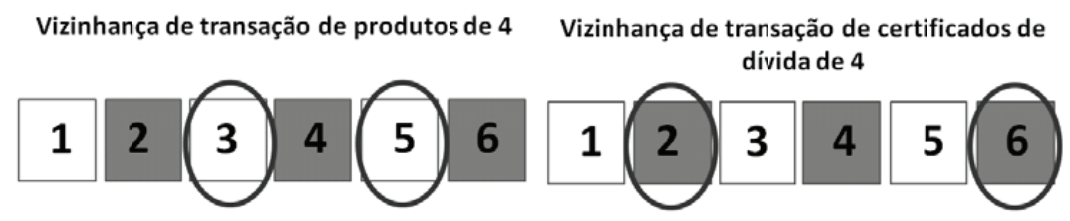

Figura 1 - Vizinhança de Transação de Produtos e Vizinhança de Transação de Certificados de Dívida.

\subsubsection{Constância das Taxas de Troca}

Não há especificação de mecanismos de formação de preços. As flutuações de preço são fontes adicionais de instabilidade econômica cuja supressão contribui, portanto, para tornar mais clara a origem e natureza da instabilidade que aqui se deseja explorar. Assume-se um preço fixo para todos os produtos ao longo das simulações, de

1 Essa formalização é de certo modo uma simplificação de estruturas produtivas, tal como podemos encontrar em Battiston et al (2007). 
modo que a taxa de troca entre dois bens quaisquer (relativo de preços) permanece também constante.

\subsubsection{Normalização da Massa Salarial em Zero}

A massa salarial é normalizada em zero para facilitar a conversão de unidades de produto no investimento necessário para produzi-las, uma vez que com isso tal investimento consistirá exclusivamente na aquisição de insumos. O fato é que, como desejamos focar as transações de produtos entre firmas, a atuação dos trabalhadores enquanto consumidores pode ser abstraída sem qualquer perda. ${ }^{2}$ Por conta disso, as empresas são, em nosso modelo, tanto as unidades de produção como de consumo dessa produção. Mas mais esclarecedor do que isso é pensá-las como unidades de investimento produtivo.

\subsubsection{O Conceito de Taxa Latente de Investimento}

O preço dos produtos será representado por $1 / \rho_{\mathrm{i}}, \mathrm{i}=1, \ldots, 36$. As variáveis $\left\{\mu_{\mathrm{ki}}\right\}$ e $\left\{\mu_{\mathrm{ji}}\right\}$, $\mathrm{j} \neq \mathrm{i}, \mathrm{k} \neq \mathrm{i}, \mathrm{i}=1, \ldots, 36$, representam, respectivamente, o número de unidades do produto da firma à esquerda $(\mathrm{k})$ e o número de unidades do produto da firma à direita $(\mathrm{j})$ de que a firma i necessita para gerar uma unidade de seu produto. A tecnologia de produção das firmas é simples: produz-se um bem a partir do processamento de dois insumos. Dessas convenções, um conceito relevante pode ser derivado. Sabemos que, para produzir uma unidade do produto i, é preciso gastar $\mu_{j i} \frac{1}{\rho_{j}}+\mu_{k i} \frac{1}{\rho_{k}}$ unidades monetárias. A razão entre esse valor e o valor de mercado de uma unidade do produto i é:. $\frac{\left(\mu_{j i} \frac{1}{\rho_{j}}+\mu_{k i} \frac{1}{\rho_{k}}\right)}{1 / \rho_{i}}=\mu_{j i} \frac{\rho_{i}}{\rho_{j}}+\mu_{k i} \frac{\rho_{i}}{\rho_{k}}=\theta_{i}$

O termo $\theta_{i}{ }^{3}$, assim obtido, doravante "taxa latente de investimento", dá-nos a proporção do valor do produto i que corresponde ao investimento necessário para produzi-lo. Tal parâmetro será compulsoriamente menor do que 1, pois do contrário teríamos firmas que precisam, para gerar uma unidade de seu produto, investir (na produção de tal unidade) um valor superior ao valor de mercado de uma unidade deste produto.

2 Foley (1986), em um modelo para os ciclos reais e de crédito, vale-se de hipótese similar: “(...) the sales of any enterprise depend on the capital out lays of the other enterprises. This is because the demand for sales arises from interfirm purchases and the spending of workers. But since workers spend their wage income instantly, worker demand is also directly determined by the capital outlays of enterprises." Assume-se, portanto, que os trabalhadores não poupam.

3 Ou simplesmente $\theta$, uma vez que o índice "i" pode ser suprimido sem qualquer perda de precisão notacional. No que segue recorre-se a essa supressão, simplificando-se, assim, a nomenclatura. 


\subsubsection{Determinação do Nível de Investimento}

Em Minsky (1975) temos uma teoria do investimento que surge como reformulação daquela que pode ser encontrada em Keynes (1936). Para fins do modelo, o fundamental em tal teoria são os passos lógicos que precedem a realização do investimento.

Minsky nos diz que os empresários, comparando a sua estimação para o valor presente do fluxo de lucros futuros, com o preço de oferta do bem de capital, fixam um nível de investimento a ser realizado no próximo período.

Quanto a isso, é preciso deixar patente que no presente modelo foca-se o investimento necessário para colocar a produção em movimento, e não, como no texto original de Minsky (1975), a aquisição de um bem de capital. ${ }^{4}$

Assim sendo, é possível restringir o horizonte da decisão do empresário a somente um período à frente. Além disso, não haverá escolha entre aplicar o capital na produção ou em ativos financeiros, por isso o elemento "preço de oferta do capital" também é abstraído. Com isso evita-se que algumas das firmas desconectem seu fluxo de caixa da dinâmica da esfera real da economia, mantendo-se o modelo fiel à meta de apreensão do problema de financiamento interno enquanto gerado na esfera mencionada.

Acabamos com uma decisão de investimento bem simplificada relativamente ao descrito por Minsky (1975): o empresário decide quanto investirá na produção no período seguinte, levando em conta o lucro que com isso espera obter. O nível de investimento que assim se obtém será chamado 'nível desejado de investimento' e a produção a ele correspondente, 'produção desejada'.

No segundo passo lógico temos que, com base nas condições de financiamento interno, dadas pelo resultado do exercício corrente (receita auferida) e com base na disponibilidade de financiamento externo, os empresários ajustam o nível de investimento desejado se tais recursos mostrarem-se insuficientes ou se o risco de tomada de crédito afigurar-se proibitivo. Abstraindo das vicissitudes atinentes à percepção do risco da operação (tanto por parte dos tomadores como concessores), temos o segundo passo do processo de obtenção do nível de investimento do modelo. Chama-se o nível de investimento que 'passa no crivo' das condições de financiamento de 'investimento futuro' e à produção correspondente de 'produção futura'.

O próximo passo lógico é uma particularidade exigida pela estrutura do modelo (ou seja, não consta em MINSKY, 1975). Dado que cada firma é tanto compradora como vendedora de insumos, o nível de investimento futuro pode mostrar-se superior à

4 Assim como é o caso em Lima \& Freitas (2007). 
oferta de insumos, o que pressupõe mais um ajuste do investimento, porém, agora, às condições de oferta. A esse nível de investimento mais uma vez ajustado é que denominamos 'investimento efetivo'. Seu emprego gera, pois, a 'produção efetiva'.

Realiza-se então o investimento, os frutos dessa empreitada são colhidos logo no próximo período, e somente em tal período, o que é coerente com o horizonte (pontual) de decisão. Com isso o investimento tem de ser repetido a cada período, de modo a manter-se, assim, a firma em operação.

\subsubsection{Temporalidade do Processo Produtivo: As Duas Fases de uma Unidade}

Em Keynes (1936) e em autores como Minsky (1975) e Robinson (1980, apud Lima: 1992), os processos econômicos em geral são pensados em tempo histórico, irreversível. Também em nosso modelo a temporalidade dos processos econômicos é levada em conta, ainda que de maneira simplificada: as empresas assumem, alternadamente no tempo, duas fases denominadas 'fase de produção' e 'fase de decisão', consistindo cada uma delas em um algoritmo específico.

Grosso modo, na fase da produção, a firma ocupa-se de comprar insumos dos vizinhos e utilizá-los para produzir. Na fase da decisão, a firma vende os produtos e, com base nisso e em sua situação financeira revelada, decide quanto será produzido na próxima fase (de produção). ${ }^{5}$ A Figura 2 abaixo ilustra como se dá a alternância entre fases, ao longo de três períodos subsequentes.

Em cada período de tempo uma firma assume uma e apenas uma fase, assumindo, no período seguinte, a fase oposta, como a Figura 2 mostra. A firma "i" está na fase de produção em $t$, enquanto que suas duas vizinhas estão, neste período, na fase de decisão. Em $\mathrm{t}+1$, o quadro se inverte, invertendo-se de novo em $\mathrm{t}+2$, e assim sucessivamente.

Esse procedimento de alternância entre duas fases comportamentais distintas é nada mais do que uma estratégia que visa tornar possível a geração de produção e de demanda por produção a partir de um conjunto de agentes "comportamentalmente" idênticos. Com isso, tanto oferta como demanda tornam-se variáveis endógenas ao modelo, sem a necessidade de incluir outros agentes que não firmas.

5 O modelo foi desenhado de modo que dois vizinhos contíguos nunca se encontrem na mesma 'fase', o que torna, portanto, possíveis as transações de produtos (e crédito) entre as unidades. Para garantir isso basta atribuir as fases alternadamente (o que é feito no algoritmo que gera as condições iniciais) e manter um número de firmas múltiplo de 6. 


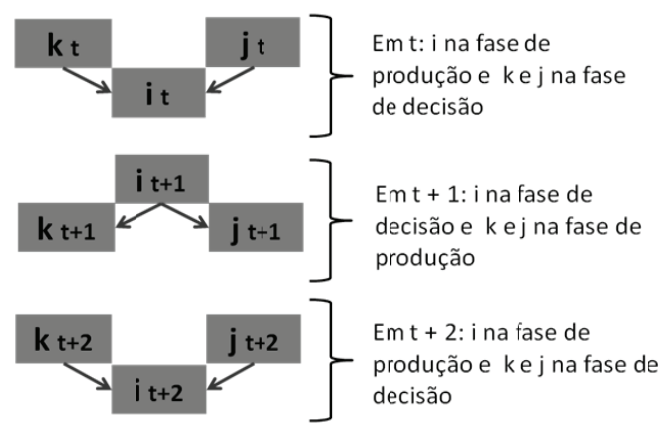

Figura 2 - Alternância das Firmas i e suas Vizinhas (k e j) entre as Fases de Decisão e Produção (as setas indicam o fluxo de produtos).

\subsection{Descrição dos Processos Realizados pelos Agentes}

\subsubsection{Transações de Produtos}

Como a Figura 3 ilustra, a transação de produtos resume-se à troca de ordens de compra emitidas pelas firmas na fase da produção (no caso 2, 4 e 6) e intenções de venda, emitidas pelas firmas na fase da decisão (no caso 1, 3 e 5), dentro do âmbito da vizinhança.

As firmas na fase de produção são demandantes de insumos, pois precisam deles para gerar o produto final. As que estão na fase de decisão são ofertantes de produtos, pois tomam como dada a produção gerada no período anterior.

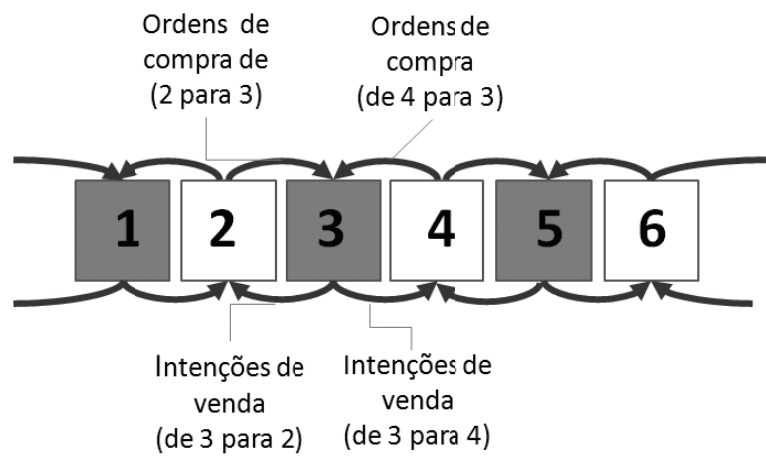

Figura 3 - Transações de Produtos 
Por conta disso, somente as firmas na fase da produção é que enviam ordens de compra de insumos (OC), sendo estas dadas por:

$$
\begin{aligned}
& O C_{k i t}=Y_{i t}^{a} \mu_{k i} \frac{1}{\rho_{k}} \\
& O C_{j i t}=Y_{i t}^{a} \mu_{j i} \frac{1}{\rho_{j}}
\end{aligned}
$$

Em que tomamos como i uma firma que está na fase da produção, $k$ o vizinho esquerdo de i e j o vizinho direito. O símbolo representa a produção-alvo fixada pela fase de decisão precedente. Os demais símbolos dizem respeito à necessidade tecnológica de insumos implícita na produção de uma unidade de produto e à conversão de unidades de produto em valor, tal como detalhado na seção 2.1.3.

No caso em que o cômputo das ordens de compra (em si o valor do investimentoalvo) excede o valor das intenções de venda recebida, a diferença é acrescentada ao patrimônio da firma.

Já a fase de decisão inicia-se sempre com a venda da produção gerada no momento anterior. É por isso que somente as firmas em tal fase enviam as seguintes intenções de oferta de produtos (representando tais intenções por IO e supondo, agora, que i encontra-se na fase da decisão):

$$
\begin{aligned}
& I O_{k i t}=A O_{i t} Y_{i t} \frac{1}{\rho_{i t}} \\
& I O_{j i t}=\left(1-A O_{i t}\right) Y_{i t} \frac{1}{\rho_{i t}}
\end{aligned}
$$

O termo "AO", doravante ajuste de oferta, nos dá a proporção (\%) da produção de i ofertada a cada vizinho ( $\mathrm{k} \mathrm{e} \mathrm{j}$ ). Utilizaremos aqui a ideia de que as unidades ajustam tal proporção de acordo com a venda realizada um período atrás, de modo a ofertar mais ${ }^{6}$ no período corrente para o vizinho que se mostrou anteriormente um melhor comprador.

6 Porém não mais do que $75 \%$ do total produzido, o que garante que não haverá oferta de menos de $25 \%$ da produção para cada um dos vizinhos, evitando, pois, o default por indisponibilidade de insumos. 
O objetivo de introduzir essa 'inteligência' está em minimizar o impacto da desconsideração da possibilidade de acumulação de estoques.

\subsubsection{Demais Processos da Fase da Produção}

Essencialmente, na fase da produção, a firma toma como dado o nível de produção decidido na fase de decisão anterior (produção futura), ajustando-o à oferta de insumos que pode encontrar, para obter o que chamamos de produção efetiva. A fase da decisão é a mais rica em termos de processos computacionais, por isso passaremos a discutir as ações a ela atinentes, na sequência em que o modelo as implementa.

\subsubsection{Cálculo do Lucro e Determinação do Investimento Desejado}

$\mathrm{Na}$ fase da decisão, a firma toma como dada a produção, vende-a para os vizinhos e aufere a massa de lucro. Essa última é dada pelo valor das vendas ou receita bruta auferida em $t$, variável a ser denotada por $A_{t}$, líquido do investimento a partir do qual a produção dos bens vendidos foi posta em movimento. Daí, a taxa de lucro $\left(r_{t}\right)$ fica sendo:

$$
r_{t}=\frac{A_{t}-I_{t}}{I_{t}}
$$

Em que $I_{t}$ é o investimento efetivo. O passo seguinte é a determinação da taxa de lucro que se espera auferir no próximo período de decisão $(\mathrm{t}+2$, se lembrarmos que entre duas fases de produção sempre há uma de decisão). Essa taxa de lucro esperada é função de três variáveis: a taxa de lucro corrente, a taxa de lucro auferida no período de decisão anterior ${ }^{7}$ e o estado de humor corrente. ${ }^{8}$

Vejamos:

$$
r_{t+2}^{e}=\left\{\begin{array}{l}
\max \left\{r_{t}, r_{t-2}\right\}, \text { se humor }=\text { otimista } \\
\min \left\{r_{t}, r_{t-2}\right\}, \text { se humor }=\text { pessimista }
\end{array}\right.
$$

7 Isso vale somente no caso em que a firma não seja nova, ou seja, no caso em que não houve default (deliberativo ou legal, tal como discutido à frente) dois períodos atrás. Na ocorrência de default a empresa que o assume é substituída por outra, que somente herda as variáveis tecnológicas, perdendo-se, assim, a informação referente às variáveis endógenas.

8 O ajuste dessa variável qualitativa é discutido adiante. 
Para determinar o nível desejado de investimento (a ser realizado na etapa da produção, em $\mathrm{t}+1$ ), cada firma vale-se de uma relação do tipo acelerador à la Robinson (Foley e Michl: 1999):

$$
\frac{I_{t+1}^{d}-I_{t}}{I_{t}}=\gamma \cdot r_{t+2}^{e}
$$

Em que $I_{t+1}^{d}$ é o investimento desejado e $\gamma$ é o parâmetro (sempre positivo) que dá a sensibilidade idiossincrática da taxa de aumento do investimento à taxa de lucro esperada. Com alguma manipulação, a equação acima assume a forma:

$$
I_{t+1}^{d}=\left(1+\gamma_{i} \cdot r_{t+2}^{e}\right) I_{t}
$$

e aí se torna possível, a partir das variáveis conhecidas pela firma em t, calcular o nível desejado de investimento.

É importante destacar que a sensibilidade da acumulação ao lucro esperado é mais um elemento que imprime heterogeneidade às firmas, sendo aleatoriamente atribuído no início da simulação.

\subsubsection{Default Deliberativo}

Antes de continuar há um importante ponto a ser mencionado: convencionase que, se a taxa de lucro esperada for inferior a zero, a unidade é retirada da simulação-i.e, não realiza nenhum dos procedimentos a seguir descritos e nem mesmo a fixação de um nível de investimento desejado-, sendo, pois, substituída por outra na próxima rodada. Quando isso ocorrer, dir-se-á que a unidade assume a postura "default-deliberativo", pois é como se resolvesse retirarse do mercado por não vislumbrar um lucro futuro minimamente aceitável.

A rationale dessa regra está no fato de que a equação aceleradora adotada pode dar um nível de investimento desejado não nulo para uma unidade que espera obter a partir dele uma massa de lucro negativo. Tal possibilidade não faz sentido no âmbito de uma economia capitalista, em que as decisões de produção se orientam pelo lucro. Exatamente porque desejamos captar essa natureza inexorável dos fenômenos econômicos estudados por Minsky (1975 e 1982), a adoção de tal regra mostra-se um imperativo. 


\subsubsection{Determinação da Posição}

Determinada a magnitude do investimento desejado, o próximo passo é a verificação de se (e em que medida) a massa de poder de compra assimilada permite cobrir tanto as obrigações contraídas no passado como o nível de investimento desejado. Nesse sentido, e, seguindo Foley (2003 e 1986), o fluxo de caixa de uma empresa é representado por:

$$
A_{t}+E_{t}=I_{t+1}^{d}+V_{t}
$$

Em que $A_{t}$ é a receita auferida ou resultado do exercício, $E_{t}$ é a conta que fecha o fluxo de caixa, a qual chamaremos posição da firma, e $V_{t}$ é a dívida a ser paga no período corrente, a qual consiste no "repagamento" do crédito previamente contraído, acrescido do rendimento prometido aos credores.

No caso da obtenção de um resultado do exercício insuficiente, teremos $E_{t}>0$, o que significa que a firma é tomadora de crédito. Se $\mathrm{E}_{\mathrm{t}}=0$, a firma não participa do mercado de crédito. No caso em que $\mathrm{E}_{\mathrm{t}}<0$, a firma é uma potencial concessora de sua sobra de caixa na qualidade de crédito.

\subsubsection{Regras de Operação do Mercado de Sobras de Caixa}

A maneira mais coerente de apresentar as transações financeiras emuladas pelo modelo é enquanto transações de sobras de caixa. As firmas com posição negativa ofertam seu poder de compra excedente para as firmas com insuficiência de financiamento interno (posição positiva).

As regras de funcionamento do mercado de sobras de caixa, ou, como passaremos a denominá-lo, mercado de certificados de dívida, são simples e análogas às da compra e venda de insumos: as transações são fechadas a partir da submissão de ordens de compra de certificados de dívida, pelas firmas de posição negativa, e da submissão de intenções de venda de certificados de dívida, por parte das firmas de posição positiva.

Valerá também uma restrição espacial para tais transações, ou seja, elas somente se darão dentro da vizinhança expandida. A Figura 4 deixa claro do que se trata, assumindo que as posições da empresa 1 e 5 são positivas e a da empresa 3 é negativa.

A oferta de certificados de dívida para cada um dos vizinhos é dada pela magnitude da posição, ou seja, a firma demanda tanto crédito quanto precisa para fechar seu 
fluxo de caixa. Porém a proporção da posição submetida como intenção de venda de certificados de dívida a cada potencial demandante (os vizinhos afastados que registram posição negativa) é ajustada a cada fase de decisão de acordo com a demanda prévia, do mesmo modo que as intenções de oferta de produtos o são.

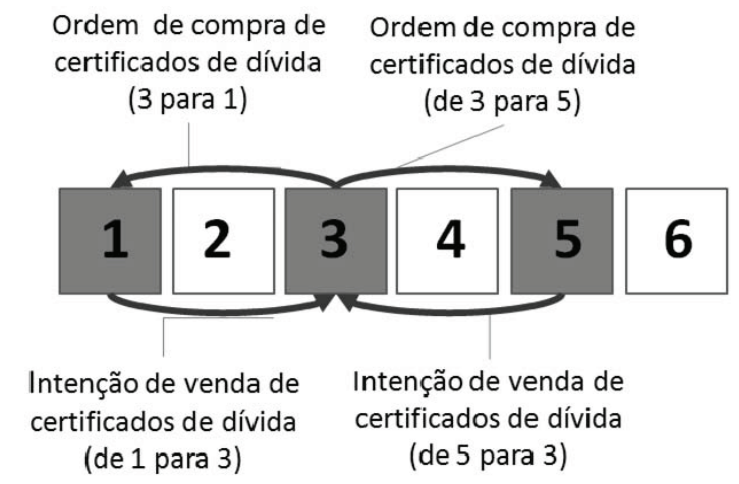

Figura 4 - Transações de Certificados de Dívida

De tal sorte temos que (supondo que i tem posição positiva):

$$
\begin{aligned}
& \operatorname{IOCD}_{\text {kit }}=A O C D_{i t} E_{i t} \\
& \operatorname{IOCD}_{j i t}=\left(1-A O C D_{i t}\right) E_{i t}
\end{aligned}
$$

em que IOCD $\mathrm{sit}_{\text {sit }}$ representa as intenções de oferta de certificados de dívida enviada por i a s, s = k ou j. O termo AOCD, o 'ajuste de oferta de certificados de dívida', dá a proporção do volume total de certificados de dívida ofertado ao vizinho afastado da esquerda, e segue a mesma lógica do termo "AO"antes visto. ${ }^{9}$

Já a ordem de compra de certificados de dívida discrimina pelo rendimento da operação: a firma com posição negativa demandará, de cada unidade que envia intenções de venda, uma proporção do valor absoluto de sua posição tão maior quanto maior for a razão entre o rendimento prometido pelo requisitante, e a soma do rendimento prometido pelos dois vizinhos (se ambos assumem posição positiva).

Assumiremos, para facilitar a organização das transações, que todas as firmas necessitadas de financiamento externo prometem pagar (no próximo período de decisão)

9 Valendo, pois, a regra de não ofertar menos do que 25\% dos certificados de dívida para ambos os vizinhos. 
um montante equivalente ao montante requisitado, ampliado por uma margem igual à taxa de lucro obtida no período corrente. ${ }^{10}$

As transações de sobras de caixa são fechadas tomando-se o valor mínimo entre as ordens de compra recebidas por uma firma e as intenções de venda enviadas.

No caso em que a demanda representada por uma unidade excede a oferta em valor, a diferença é entesourada.

No período de decisão posterior àquele em que houve venda de certificados de dívida por uma empresa, essa deverá pagar o prometido aos compradores, se não assumir o estado de default legal (definição à frente). Os rendimentos financeiros recebidos são somados ao patrimônio acumulado.

Depreende-se do exposto que a decisão de quanto produzir/investir pode ser apreendida como causa causans tanto da oferta de sobras de caixa, como da demanda por sobras de caixa de outrem. Isso, pois, supõe-se que a magnitude da oferta de e da demanda por sobras de caixa são ambas equivalentes à magnitude da posição $\left(E_{t}\right)$. Em segundo lugar, o nível de investimento desejado é o único determinante da posição da firma que resulta da tomada de decisão por parte da mesma. Fica, portanto, explícita a dominância do lado real sobre o lado financeiro, inerente ao modelo.

\subsubsection{Atribuição de Posturas}

Após realizar as devidas transações financeiras, a cada firma, com base no volume de recurso levantado, atribuir-se-á uma postura financeira, de acordo com a taxonomia minskyana (MINSKY, 1982 e FOLEY, 2003). As posturas são definidas da seguinte forma:

- Se comprador de certificados de dívida ou não participante do mercado de crédito em $\mathrm{t}\left(\mathrm{E}_{\mathrm{t}} \leq 0\right)$, a firma assume postura hedge. Trata-se do grau mínimo de fragilidade financeira.

- $\quad$ Se vendedor de certificados de dívida em $t\left(E_{t}>0\right)$ :

i. $A_{t} \geq V_{t}$, a firma assume postura especulativa. Trata-se do grau intermediário de fragilidade financeira;

10 Isso é o mesmo que dizer que os tomadores de crédito prometem aos credores um rendimento na operação equivalente à taxa de lucro auferida pelos primeiros no presente.

Est. Econ., São Paulo, 41(1): 197-228, jan.-mar. 2011 
ii. $A_{t}<V_{t}$, a firma assume postura Ponzi. Trata-se do grau máximo de fragilidade financeira.

\subsubsection{Reconsideração do Nível Desejado de Investimento e Default Legal}

As unidades hedge não precisam reconsiderar o nível de investimento desejado, por definição. Porém, se a postura obtida não for hedge, as unidades devem reconsiderar a decisão de investimento desejado, tendo em vista o volume de financiamento interno (receita auferida no período) e externo levantado (venda de certificados de dívida). Tal reconsideração se dá a partir do seguinte algoritmo:

(i) Pergunta-se à firma: É possível cobrir a dívida e o investimento desejado a partir do financiamento interno e externo?

(ii.a) No caso em que a avaliação de (i) é positiva, o nível de investimento desejado é plenamente implementado;

(ii.b) Porém, mostrando-se (i) negativa, pergunta-se à firma: É possível cobrir a dívida e o investimento desejado a partir do financiamento interno, externo e do patrimônio?

(ii.b.l) Sendo a resposta para (ii.b) positiva, o nível de investimento desejado é plenamente implementado, ajustando-se o patrimônio na magnitude dilapidada;

(ii.b.2) Porém, mostrando-se (ii.b.l) negativa, pergunta-se à firma: É possível cobrir a dívida e a replicação do investimento efetivo para o próximo período (uma vez que esse é sempre menor do que o nível de investimento desejado, vide equação 8), a partir do financiamento interno, externo e do patrimônio?

(ii.b.2.a) Se a resposta a (ii.b.2) for afirmativa, o investimento a ser realizado será equivalente ao investimento efetivo corrente, e o patrimônio será corrigido pela magnitude dilapidada;

(ii.b.2. $\beta$ ) No caso em que a resposta a (ii.b) é negativa, a firma assume o estado de default legal. 


\subsubsection{Atualização do humor}

A transição entre os dois estados possíveis de humor segue os princípios: (i) se humor = otimista e a postura assumida é não-hedge, a empresa passará a pessimista no próximo período e; (ii) se humor = pessimista e a postura assumida é hedge, a empresa passará a otimista no próximo período. Nas demais possibilidades o estado de humor não é alterado.

\subsubsection{Substituição de Empresas que Assumem Default Legal ou Deliberativo}

Assim que uma firma assume um dos dois estados de default, ela não mais realiza procedimentos. Na próxima iteração do algoritmo, há a entrada de uma nova firma substituta, a qual herda apenas as características tecnológicas da que assumiu default.

\section{Fundamentos "Reais" da Postura Financeira Assumida por uma Firma}

(i) É possível reescrever o fluxo de caixa de uma unidade da seguinte maneira:

$E_{t}=I_{t+1}^{d}-A_{t}+V_{t}=R_{t}+V_{t}$

Em que $R_{t}$ representa a magnitude do financiamento externo necessária para cobrir o investimento desejado. Tomando isoladamente $\mathrm{R}_{\mathrm{t}}$, pode-se realizar algumas manipulações algébricas esclarecedoras. Para isso é preciso avaliar cada um dos componentes de $\mathrm{R}_{\mathrm{t}}$.

(ii) $\mathrm{A}_{\mathrm{t}}=\alpha_{\mathrm{t}} \mathrm{Y}_{\mathrm{t}} / \rho$, em que $\alpha_{\mathrm{t}}$ é proporção do valor da produção realizado em $t$, ou simplesmente, a taxa de realização.

(iii) Como $\mathrm{I}_{\mathrm{t}}=\theta \mathrm{Y}_{\mathrm{t}} / \rho \rightarrow \mathrm{A}_{\mathrm{t}}=\alpha_{\mathrm{t}} \mathrm{I}_{\mathrm{t}} / \theta$.

(iv) $r_{t}=\frac{A_{t}-I_{t}}{I_{t}}=\frac{\alpha_{t} Y_{t} / \rho-\theta Y_{t} / \rho}{\theta Y_{t} / \rho}=\frac{\alpha_{t}-\theta}{\theta}$

(v) $I_{t+1}^{d}=\left(1+\gamma r_{t+2}^{e}\right) I_{t}$

Levando (ii) e (iii) em consideração, existem três possibilidades a serem avaliadas:

(vi.a) $r_{t+2}^{e}=r_{t} \neq 0$

(vi.b) $r_{t+2}^{e}=r_{t-2} \neq 0$ 
(vi.c) $r_{t+2}^{e}=0$

Como os casos de default-deliberativo, caracterizados por $r_{t+2}^{e}<0$, não representam uma postura financeira, podem ser suprimidos da análise da presente seção, a qual visa chegar aos determinantes da atribuição de posturas. Como isso, pode-se modificar (vi.a) e (vi.b) para:

(vi.a') $\quad r_{t+2}^{e}=r_{t}>0$

(vi.b') $r_{t+2}^{e}=r_{t-2}>0$

(vii.a) Combinando (iv), (v) e (vi.a'), obtém-se: $I_{t+1}^{d}=\left[1+\gamma\left(\frac{\alpha_{t}-\theta}{\theta}\right)\right] I_{t}$

(viii.a) Levando (vii.a) e (iii) na definição de $\mathrm{R}_{\mathrm{t}}: R_{t}=\left[1+\gamma\left(\frac{\alpha_{t}-\theta}{\theta}\right)\right] I_{t}-\frac{\alpha_{t} I_{t}}{\theta}$

Com alguma manipulação, pode-se chegar a: $R_{t}=\left(1-\frac{\alpha_{t}}{\theta}\right)(1-\gamma) I_{t}$

(ix.a) Seja S(.) a função definida por: $S(x)=\left\{\begin{array}{c}+1, \text { se } x>0 \\ 0, \text { se } x=0 \\ -1, \text { se } x<0\end{array}\right.$

(x.a) dado que se impõe, nas simulações, $\gamma \leq 0,8$ (e, também, $I_{t} \geq 0$ ), o resultado obtido em (viii.a) implica que $S\left(R_{t}\right)=S\left(1-\frac{\alpha_{t}}{\theta}\right) \rightarrow S\left(R_{t}\right)=(-1) S\left(\alpha_{t}-\theta\right)$, uma vez que $S\left(1-\frac{\alpha_{t}}{\theta}\right)=(-1) S\left(\alpha_{t}-\theta\right)$

(vii.b) Agora, combinando (iii), (iv), (v), (vi.b’), e a definição de $R_{t}$, obtém-se, com alguma manipulação:

$$
R_{t}=\left[1-\frac{1}{\theta}\left(\frac{\alpha_{t}-\alpha_{t-2}}{1-\gamma}\right)\right](1-\gamma) I_{t}
$$

Denominando $\alpha_{\mathrm{t}-2} / \alpha_{\mathrm{t}}$ por $\delta_{\mathrm{t}}$, pode-se escrever:

$$
R_{t}=\left[1-\frac{\alpha_{t}}{\theta}\left(\frac{1-\delta_{t} \gamma}{1-\gamma}\right)\right](1-\gamma) I_{t}
$$

Denotando-se $\left(\frac{1-\delta_{t} \gamma}{1-\gamma}\right)$, por $\mu_{\mathrm{t}}$, obtém-se, finalmente, 


$$
R_{t}=\left[1-\frac{\alpha_{t} \mu_{t}}{\theta}\right](1-\gamma) I_{t} \rightarrow S\left(R_{t}\right)=(-1) S\left(\alpha_{t} \mu_{t}-\theta\right)
$$

(viii.b) Em (vii.b) dois casos são possíveis:

(viii.b.1) $\alpha_{\mathrm{t}}=\alpha_{\mathrm{t}-2} \rightarrow \mu_{\mathrm{t}}=1 \rightarrow(-1) \mathrm{S}\left(\alpha_{\mathrm{t}} \mu_{\mathrm{t}}-\theta\right)=(-1) \mathrm{S}\left(\alpha_{\mathrm{t}}-\theta\right)$, e aí retoma-se (viii.a);

(viii.b.2) $\alpha_{\mathrm{t}} \neq \alpha_{\mathrm{t}-2}$. Essa possibilidade tem de ser analisada em detalhe. Para isso, cabe observar que $(-1) S\left(\alpha_{t} \mu_{t}-\theta\right)=(-1) S\left[\left(\alpha_{t}\left(\mu_{t}-1\right)+\left(\alpha_{t}-\theta\right)\right]=(-1) S\left[\gamma\left(\alpha_{t}-\alpha_{t-2}\right)+\left(\alpha_{t}-\theta\right)\right]\right.$, em que, na última passagem retomou-se a definição de $\mu_{\mathrm{t}}$. Tem-se, portanto, que o valor do sinal de $\mathrm{R}_{\mathrm{t}}$ dependerá, no caso avaliado, não apenas da magnitude em que a taxa de realização corrente supera a taxa latente de investimento, mas também da magnitude em que a taxa de realização corrente supera a taxa de realização passada. Mas a importância de cada um desses componentes não é equivalente. Basta escrever: $\mathbf{S}\left\{(1+\gamma)\left[\gamma /(1+\gamma)\left(\alpha_{t}-\alpha_{t-2}\right)+1 /(1+\gamma)\left(\alpha_{t}-\theta\right)\right]\right\}=S\left[\gamma /(1+\gamma)\left(\alpha_{t}-\alpha_{t-2}\right)+1 /(1+\gamma)\left(\alpha_{t}-\theta\right)\right]$. Como $\gamma \leq 0,8<1$, o peso da discrepância entre a taxa de realização corrente e a taxa latente de investimento é maior do que o atribuído, pelo modelo, à discrepância entre a taxa de realização corrente e a taxa de realização passada, no caso em que $r_{t+1}^{e}=r_{t-2} \neq 0$ e $\alpha_{\mathrm{t}} \neq \alpha_{\mathrm{t}-2}$. Isso para fins de determinação do sinal de $\mathrm{R}_{\mathrm{t}}$. É possível dividir a análise do caso em vista (viii.b.2) em duas etapas:

(viii.b.2.A) Se $r_{t+2}^{e}=\mathrm{r}_{\mathrm{t}-2}$ e $r_{t+2}^{e}>0 \rightarrow \mathrm{r}_{\mathrm{t}-2}>0 \rightarrow \alpha_{\mathrm{t}-2}>\theta$ (vide (iv) acima). Se $\alpha_{\mathrm{t}}>\alpha_{\mathrm{t}-2} \rightarrow$

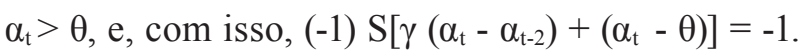

(viii.b.2.B) Sendo, porém, $\alpha_{t}<\alpha_{t-2}$, tem-se que:

$$
\left\{\begin{array}{l}
(-1) \operatorname{S}\left[\gamma\left(\alpha_{t}-\alpha_{t-2}\right)+\left(\alpha_{t}-\theta\right)\right]=+1 \text {, se } \frac{\left|\alpha_{t}-\theta\right|}{\left|\alpha_{t}-\alpha_{t-2}\right|}<\gamma \\
(-1) \operatorname{S}\left[\gamma\left(\alpha_{t}-\alpha_{t-2}\right)+\left(\alpha_{t}-\theta\right)\right] \neq+1 \text {, se } \frac{\left|\alpha_{t}-\theta\right|}{\left|\alpha_{t}-\alpha_{t-2}\right|} \geq \gamma
\end{array}\right.
$$

O resultado ora obtido deixa mais claro o fato de que a função desempenhada por $\gamma$ é a de atribuir a relação entre as magnitudes de $\alpha_{t}-\alpha_{t-2}$ e $\alpha_{t}-\theta$ que tem de ser atingida para que o valor assumido pelo financiamento externo para o investimento desejado $\left(\mathrm{R}_{\mathrm{t}}\right.$ ) favoreça uma postura financeira frágil (não-hedge) ou não (hedge).

Mas isso apenas quando $r_{t+2}^{e}=r_{t-2} e \alpha_{t}<\alpha_{t-2}$, em toda as demais situação possíveis, $\gamma$ não desempenha qualquer papel na determinação de $S\left(R_{t}\right)$. 
(vii.c) É trivial demonstrar que, a partir de (iii), (iv), (v) e (vi.c), tem-se que:

$$
R_{t}=\left(1-\frac{\alpha_{t}}{\theta}\right) I_{t} \rightarrow S\left(R_{t}\right)=(-1) S\left(\alpha_{t}-\theta\right)
$$

Reunindo os resultados (x.a), (viii.b.2.A), (viii.b.2.B) e (vii.c), chega-se a que, levando-se em conta todas as possibilidades para a função $r_{t+2}^{e}$ :

$S\left(R_{t}\right)=\left\{\begin{array}{c}(-1) S\left(\alpha_{t}-\theta\right), \text { se } r_{t+2}^{e}=0 \text { ou } r_{t+2}^{e}=r_{t} \neq 0 \text { ou } r_{t+2}^{e}={ }_{t-2} \neq 0 \text { e } \alpha_{t}=\alpha_{t-2} \\ (-1) S\left(\alpha_{t} \mu_{t}-\theta\right), \text { se } r_{t+2}^{e}=r_{t-2} \neq 0 \text { e } \alpha_{t} \neq \alpha_{t-2}\end{array}\right.$

Voltando em (i), tem-se que $S\left(E_{t}\right)=S\left(R_{t}+V_{t}\right)$, o que implica as seguintes condições:

(Cl) $S\left(E_{t}\right)=+1 \leftrightarrow S\left(R_{t}\right)=+1$, dado que $S\left(V_{t}\right)=+1$, por definição.

Recordando os critérios utilizados para atribuir as posturas financeiras às unidades (vide seção 2.3.7), a condição que se acaba de enunciar deve ser lida da seguinte maneira: a unidade é não-hedge se, e somente se, necessita de financiar externamente (ao menos em parte) o nível desejado de investimento;

(C2) Se $S\left(E_{t}\right)=-1 \rightarrow S\left(R_{t}\right)=-1$, porém não vale a implicação contrária, i.e., $S\left(R_{t}\right)$ $=-1$ não implica em $S\left(E_{t}\right)=-1$.

(C3) Se $S\left(E_{t}\right)=0 \rightarrow S\left(R_{t}\right) \neq+1$

As duas últimas condições podem ser reunidas em apenas uma:

$\left(C 2^{\prime}\right)$ Se $S\left(E_{t}\right) \neq+1 \rightarrow S\left(R_{t}\right) \neq+1$. I.e., se a unidade é hedge, então há capacidade para financiar internamente o investimento desejado.

Pode-se concluir, portanto, conjugando (R1), (C1) e (C2'), que:

(P1) Se $r_{t+2}^{e}=0$ e $\alpha_{\mathrm{t}}<\theta$ ou; (b) $r_{t+2}^{e}=r_{t}>0$ e $\alpha_{\mathrm{t}}<\theta$ ou; (c) $r_{t+2}^{e}=r_{t-2}>0$ e $\alpha_{\mathrm{t}}=\alpha_{\mathrm{t}} \mathrm{e}$ $<\theta \leftrightarrow$ a unidade é não-hedge em t;

(P2) Se $r_{t+2}^{e}=r_{t-2}>0$ e $\alpha_{\mathrm{t}}<\alpha_{\mathrm{t}-2}$ e $\frac{\left|\alpha_{\mathrm{t}}-\theta\right|}{\left|\alpha_{\mathrm{t}}-\alpha_{\mathrm{t}-2}\right|}<\gamma \leftrightarrow$ a unidade é não-hedge em t;

(P3) Se (a) $r_{t+2}^{e}=0$ e $\alpha_{t} \geq \theta$ ou; (b) $r_{t+2}^{e}=r_{t}>0$ e $\alpha_{\mathrm{t}} \geq \theta$ ou; (c) $r_{t+2}^{e}=r_{t-2}>0$ e $\alpha_{\mathrm{t}}=\alpha_{\mathrm{t}-2}$ e $\alpha_{\mathrm{t}} \geq \theta \rightarrow$ a unidade tende a ser hedge em $\mathrm{t}$; 
(P4) Se (a) $r_{t+2}^{e}=r_{t-2}>0$ e $\alpha_{\mathrm{t}}>\alpha_{\mathrm{t}-2}$; ou (b) $r_{t+2}^{e}=r_{t-2} \neq 0$ e $\alpha_{\mathrm{t}}<\alpha_{\mathrm{t}-2}$ e $\frac{\left|\alpha_{\mathrm{t}}-\theta\right|}{\left|\alpha_{\mathrm{t}}-\alpha_{\mathrm{t}-2}\right|} \geq \gamma \rightarrow$ a unidade tende a ser hedge em $\mathrm{t}$.

$\mathrm{Ou}$, mais sinteticamente:

(S1) Se $\mathrm{S}\left(\mathrm{R}_{\mathrm{t}}\right)>0 \leftrightarrow$ a unidade é não-hedge em t (agregando P1 e P2);

$(\mathrm{S} 2)$ Se $\mathrm{S}\left(\mathrm{R}_{\mathrm{t}}\right) \leq 0 \rightarrow$ a unidade tende a ser hedge em $t$ (agregando P3 e P4).

Em que $S\left(R_{t}\right)$ é tal como definido em $(R)$.

Enquanto Pl.a, P1.b, Pl.c, P2 e, portanto, S1, são condições suficientes e necessárias para que uma unidade seja não-hedge, $\mathrm{P} 3, \mathrm{P} 4$ e, portanto, S2, são apenas condições necessárias para que uma unidade seja hedge. Nesses últimos dois princípios, a força da tendência apontada depende da magnitude de $R_{t}$ vis a vis a de $V_{t}$ (a dívida a ser honrada em $\mathrm{t}$ ).

Chega-se, portanto, à conclusão de que é possível formular condições para que uma unidade assuma postura hedge ou não-hedge levando em consideração apenas uma variável endógena, $\alpha-$ a taxa de realização do valor da produção - e apenas duas variáveis exógenas, $\theta$ e $\gamma-$ a taxa latente de investimento e a sensibilidade do investimento à taxa de lucro esperada - como sugerido em P1, P2, P3 e P4.

Trata-se de uma redução considerável do problema de apreensão da dinâmica do modelo, cuja importância está em permitir a elaboração de uma explicação para o processo de transição da postura hedge para a postura não-hedge, sintética e estritamente com base em variáveis atinentes ao que geralmente se denomina de "lado real" da economia, i.e., as esferas da produção e da realização da produção. ${ }^{11}$ Uma vez que a natureza das variáveis em questão é microeconômica, é mais rigoroso referir-se a elas como próprias à dimensão da atividade produtiva de uma empresa, ao invés de utilizar-se a imagem da economia como um todo.

No que segue, o conjunto formado pelas condições (P1) a (P4) será denominado de "princípio de determinação da postura a partir do vetor $\left\{\alpha_{t}-\theta, \alpha_{t}-\alpha_{t-2}, \gamma\right\}$ " e o conjunto formado pelas condições (S1) e (S2) de "princípio de determinação da postura a partir do sinal de $\mathrm{R}_{\mathrm{t}}$ ". A relação existente entre esses dois conjuntos de condições é clara: (P1) a (P4) se colocam como fundamentos de (S1) e (S2), já que o sinal de

11 Quanto a isso, basta assinalar que $\gamma$ é um dos determinantes da tomada de decisão sobre o nível futuro de investimento (e, por decorrência, sobre o nível futuro de produção), $\theta$ determina a proporção do valor da produção a que corresponde o investimento que tem de ser feito para gerála, e $\alpha_{\mathrm{t}}$ e $\alpha_{\mathrm{t}-2}$ emergem como resultados da realização da produção. 
$R_{t}$ é determinado pelo vetor $\left\{\alpha_{t}-\theta, \alpha_{t}-\alpha_{t-2}, \gamma\right\}$. Utilizar-se-á, pois, intercambiavelmente as duas denominações que se acaba de propor para denotar o princípio a que se pôde chegar na presente seção, o qual deve ser entendido como uma regra de determinação de posturas financeiras com base, exclusivamente, em um conjunto de variáveis circunscritas à esfera real da economia.

\section{Resultados das Simulações}

\subsection{Condições Iniciais}

O número de unidades de cada produto adquirido por uma unidade monetária $(\rho)$ é aleatoriamente sacado do intervalo $\{0,1 ; 1\} \in Z$-, o preço dos produtos $(1 / \rho)$ se mantém, pois, no intervalo $\{1,10\}$. Os parâmetros tecnológicos, $\mu_{\mathrm{ki}}$ e $\mu_{\mathrm{ji}}$, são sorteados do intervalo $\left\{0, \delta_{\mathrm{s}}\right\} \in Z$, em que $\delta_{\mathrm{s}}, \mathrm{s}=\mathrm{k}$, para $\mu_{\mathrm{ki}}$ ou $\mathrm{j}$ para $\mu_{\mathrm{ji}}$, é fixado de modo a ter-se $\theta \leq 0,5$.

As firmas têm como condição inicial uma produção cuja magnitude é aleatoriamente retirada do intervalo $\{0,100\} \in Z$, sendo medida em unidades de produto. Vale-se do artifício de atribuir um nível de produção igual a 50 às firmas que são contempladas pelo gerador de números aleatórios com uma condição inicial 0 . Com base na produção aleatoriamente gerada, obtém-se o investimento, multiplicando a primeira por $\theta$. $O$ patrimônio inicial é também sacado do intervalo $\{0,100\} \in Z$, valendo a regra de não nulidade praticada para a produção.

Para as demais condições iniciais, valem os princípios:

- O parâmetro de sensibilidade " $\gamma$ " é sacado aleatoriamente do intervalo $\{0 ; 0,8\} \in$ Z. Se o sorteio apresentar um número menor do que 0,1 como resultado, fixa-se $\gamma$ em 0,1

- O humor é aleatoriamente atribuído a cada unidade;

- Os parâmetros de equilíbrio para transação de produtos $(\mathrm{AO})$ e certificados de dívida (AOCD) são inicialmente 0,5 ;

- Nenhuma unidade entra com dívida a ser paga;

- Todas as unidades são inicialmente hedge. 


\subsection{O Modelo em Funcionamento}

Como mostram as figuras abaixo, a economia hipotética simulada pelo modelo apresenta duas características condizentes com a concepção pós-keynesiana de uma economia capitalista. A Figura 5 indica um comportamento cíclico, em que períodos de elevação do valor agregado da produção são seguidos de períodos de queda do valor agregado da produção. Já, conforme se vê na Figura 6, períodos de elevação da proporção de unidades não-hedge (especulativas ou Ponzi) são seguidos por períodos de queda desta proporção. Tem-se, portanto, o estado de permanente alternância entre momentos de maior fragilidade e momentos de menor fragilidade, vislumbrado por Minsky $(1975,1982)$.

Para efeito de análise de resultados, denominou-se de "experimento" um conjunto de 4.439 iterações consecutivas do modelo computacional, a partir de um conjunto específico de sementes aleatórias para as condições iniciais.

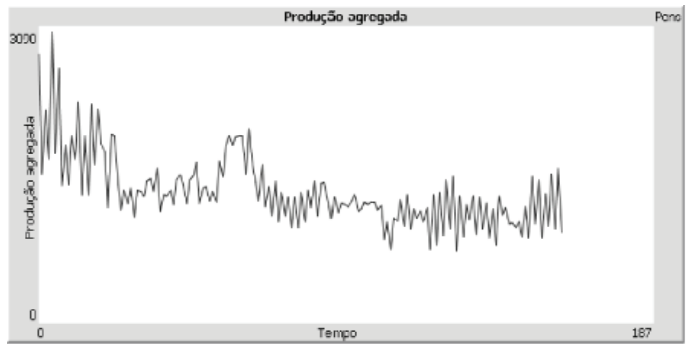

(A) 123 iterações

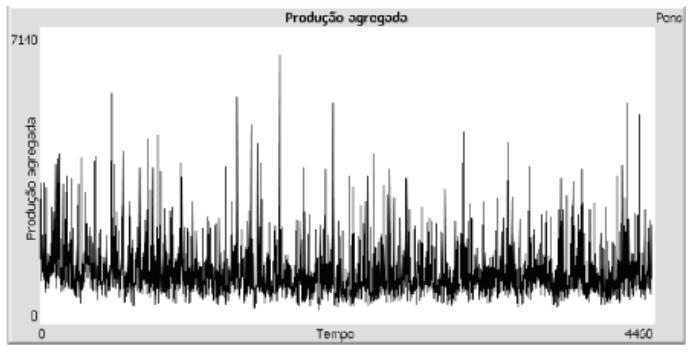

(B) 4.439 iterações

Figura 5 - o comportamento do valor agregado da produção em um experimento representativo (para tal característica).

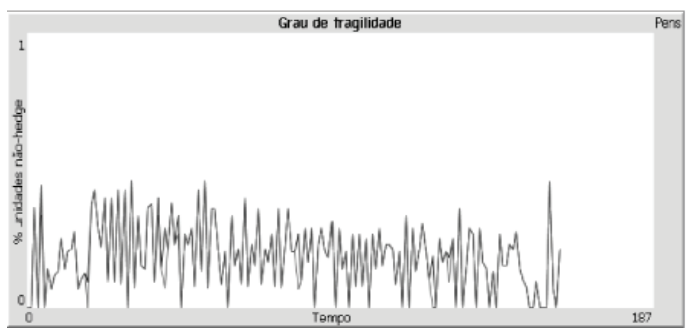

(A) 123 iterações

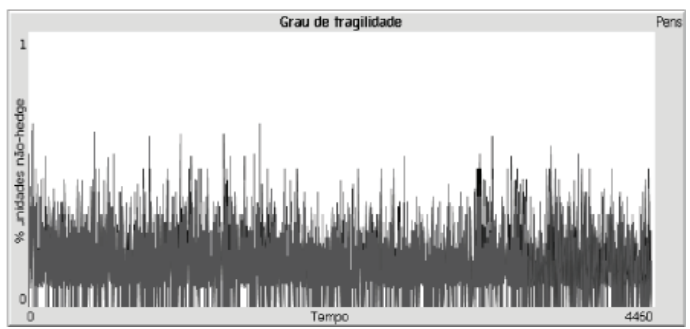

(B) 4.439 iterações

Figura 6 - o comportamento da proporção de unidades não-hedge na economia em um experimento representativo (para tal característica). 


\subsection{Análise dos Resultados}

\subsubsection{Teste "Estático" para o Princípio de Determinação da Postura a partir do Vetor $\left\{\alpha_{t}-\theta, \alpha_{t}-\alpha_{t-2}, \gamma\right\}$}

É preciso verificar se o modelo gera resultados que se coadunam com o princípio formulado na seção 3. Como primeiro teste, contou-se o número de vezes que cada uma das quatro tipologias apresentadas na tabela abaixo se manifestou ao longo de trinta experimentos.

Tabela 1 - Tipologias para o Cruzamento da Informação Referentes à Postura e ao Sinal de Rt

\begin{tabular}{|c|c|c|}
\hline Postura /Sinal de $\mathrm{R}_{\mathrm{t}}$ & $S\left(R_{t}\right) \neq \neq+1$ & $S\left(R_{t}\right)=+1$ \\
\hline Hedge & Tipologia 1 & Tipologia 3 \\
\hline Não-hedge & Tipologia 2 & Tipologia 4 \\
\hline
\end{tabular}

Seja a probabilidade frequentista da tipologia "i", (i=1, 2, 3 ou 4), dada por $\mathrm{P}\left(\mathrm{T}_{\mathrm{i}}\right)$

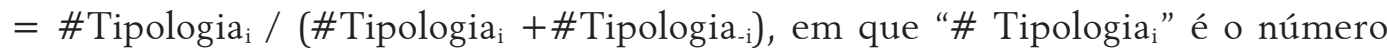
de ocorrências da tipologia i (frequência absoluta), "-i" é a outra tipologia com um valor para $S\left(R_{t}\right)$ equivalente ao da tipologia i. Deste modo, $\mathrm{P}(\mathrm{Ti})=\mathrm{P}$ (Postura correspondente a i | Sinal de $\mathrm{R}_{\mathrm{t}}$ ), em que $\mathrm{P}(\mathrm{x} \mid \mathrm{y})$ é a probabilidade de ocorrência do evento $\mathrm{x}$ condicional à ocorrência prévia do evento $\mathrm{y}$. A verificação do princípio de determinação da postura a partir do sinal de $\mathrm{R}_{\mathrm{t}}$ pressupõe a não refutação das premissas $\mathrm{P}\left(\mathrm{T}_{1}\right)>\mathrm{P}\left(\mathrm{T}_{2}\right)$ e $\mathrm{P}\left(\mathrm{T}_{3}\right)<\mathrm{P}\left(\mathrm{T}_{4}\right)$. Trata-se, portanto, de verificar se as relações postuladas entre o sinal de $R_{t}$ e a postura de uma unidade (vide $S 1$ e S2, seção 3) são corroboradas pela simulação do modelo computacional. ${ }^{12}$

A tabela abaixo apresenta os valores assumidos pelas probabilidades frequentistas sob consideração, para os 10 primeiros experimentos de uma sequência de 30 experimentos.

Chega-se a um resultado de grande importância. O princípio, formulado na seção 3, em sua versão sintética (S1 e S2, seção 3) é composto por uma condição necessária

$12 \mathrm{O}$ sinal de $\mathrm{R}_{\mathrm{t}}$ foi calculado a partir da condição (R) da seção 3 . 
e suficiente e uma condição necessária. ${ }^{13}$ A última deve, portanto, ser vista apenas como uma lei tendencial para que uma unidade assuma a postura hedge, e sua efetivação depende de variáveis que não se circunscrevem à esfera real da economia, as quais estão sintetizadas no valor corrente da dívida $\left(\mathrm{V}_{\mathrm{t}}\right)$. Isso nos diz que o princípio de que o vetor $\left\{\alpha_{\mathrm{t}}-\theta, \alpha_{\mathrm{t}}-\alpha_{\mathrm{t}-2}, \gamma\right\}$ determina a postura de uma unidade como hedge ou não-hedge não vale matematicamente.

Tabela 2 - Probabilidades de Ocorrência das Tipologias Definidas na Tabela 1, ao longo de 30 Experimentos.

\begin{tabular}{ccccc}
\hline Experimento & $\mathrm{P}(\mathrm{T} 1)$ & $\mathrm{P}(\mathrm{T} 2)$ & $\mathrm{P}(\mathrm{T} 3)$ & $\mathrm{P}(\mathrm{T} 4)$ \\
\hline 1 & $96,30 \%$ & $3,70 \%$ & $0,00 \%$ & $100,00 \%$ \\
2 & $97,10 \%$ & $2,90 \%$ & $0,00 \%$ & $100,00 \%$ \\
3 & $99,60 \%$ & $3,40 \%$ & $0,00 \%$ & $100,00 \%$ \\
4 & $95,30 \%$ & $4,70 \%$ & $0,00 \%$ & $100,00 \%$ \\
5 & $95,60 \%$ & $4,40 \%$ & $0,00 \%$ & $100,00 \%$ \\
6 & $97,90 \%$ & $2,10 \%$ & $0,00 \%$ & $100,00 \%$ \\
7 & $96,40 \%$ & $3,60 \%$ & $0,00 \%$ & $100,00 \%$ \\
8 & $98,20 \%$ & $1,80 \%$ & $0,00 \%$ & $100,00 \%$ \\
9 & $95,40 \%$ & $4,60 \%$ & $0,00 \%$ & $100,00 \%$ \\
10 & $96,10 \%$ & $3,90 \%$ & $0,00 \%$ & $100,00 \%$ \\
$\ldots$ & $\ldots$ & $\ldots$ & $\ldots$ & $\ldots$ \\
$C D$ & $1,10 \%$ & $31,30 \%$ & - & - \\
\hline
\end{tabular}

$\mathrm{CD}=$ coeficiente de dispersão (desvio-padrão para os valores ao longo da coluna / média para os valores ao longo da coluna), os casos em que não foi possível calculá-lo (aqueles em que os valores assumidos ao longo dos experimentos se mantiveram sem alteração) estão marcados com "-".

$\mathrm{O} C D$ foi calculado a partir dos resultados dos 30 experimentos.

Mas o que fica comprovado, com os resultados dos 30 experimentos realizados, é que o princípio em questão vale estatisticamente, já que não mais do que $5 \%$ das unidades com sinal não positivo para $\mathrm{R}_{\mathrm{t}}$ apresentaram postura hedge, enquanto todas as unidades com sinal positivo para $\mathrm{R}_{\mathrm{t}}$ apresentaram postura não-hedge.

É possível compreender o resultado obtido na presente subseção de um modo alternativo. Ele garante que, mesmo não estando disponíveis dados que permitam calcular o fluxo de caixa de uma unidade, é possível classificar a unidade em questão como hedge ou não-hedge. Basta, para isso, aplicar as regras que compõem o princípio enunciado na sub-seção anterior (Pl a P4), o que exige o conhecimento

13 Na versão "não sintética" do princípio, composta por (Pl) a (P4), as duas primeiras condições são suficientes e necessárias, e as demais apenas necessárias. 
É possível compreender o resultado obtido na presente subseção de um modo alternativo. Ele garante que, mesmo não estando disponíveis dados que permitam calcular o fluxo de caixa de uma unidade, é possível classificar a unidade em questão como hedge ou não-hedge. Basta, para isso, aplicar as regras que compõem o princípio enunciado na subseção anterior ( $\mathrm{Pl}$ a $\mathrm{P} 4)$, o que exige o conhecimento de apenas três variáveis, $\alpha_{\mathrm{t}}-\theta, \alpha_{\mathrm{t}}-\alpha_{\mathrm{t}-2}$ e $\gamma$, as quais dizem respeito, estritamente, à dimensão das atividades produtivas de uma empresa. Tal expediente gera uma classificação equivocada para não mais do que $5 \%$ das unidades a ele submetidas.

\subsubsection{Testes Dinâmicos para o Princípio de Determinação da Postura na Esfera Real}

É interessante verificar se o princípio de determinação da postura a partir do sinal de $\mathrm{R}_{\mathrm{t}}$ é corroborado dinamicamente, comparando-se a postura e o sinal de $\mathrm{R}_{\mathrm{t}}$ assumidos pelas unidades em dois períodos de tempo. ${ }^{14}$ Para isso, classificaram-se as unidades de acordo com a postura por elas assumida em duas fases de decisão subsequentes. As unidades que, entre dois períodos de decisão subsequentes, sofreram a transição para uma postura de maior grau de fragilidade financeira, foram classificadas como casos de fragilização financeira. Inversamente, as unidades que se tornaram menos frágeis foram classificadas como casos de "fortalecimento financeiro". Os demais casos, i.e., aqueles em que não houve mudança no grau de fragilidade, foram classificados como casos de "não transição". Cruzando essas três possibilidades de classificação pela transição entre posturas financeiras, com a classificação pela transição entre valores distintos para o sinal de $R_{t}$, pôde-se chegar às tipologias apresentadas na tabela abaixo.

Tabela 3 - Tipologias para o Cruzamento da Informação Referente à Transição de Postura com a Informação Referente à Alteração do Sinal de $\mathbf{R}_{t}$

\begin{tabular}{|c|c|c|c|c|}
\hline $\begin{array}{c}\text { Transição de postura / Alteração } \\
\text { do sinal de } R_{t}\end{array}$ & $\begin{array}{c}S\left(R_{t-1}\right) \neq+1 \rightarrow \\
S\left(R_{t}\right)=+1 \\
(\text { Grupo 1) }\end{array}$ & $\begin{array}{c}S\left(R_{t-1}\right)=+1 \rightarrow \\
S\left(R_{t}\right)=+1 \\
(\text { Grupo 2) }\end{array}$ & $\begin{array}{c}S\left(R_{t-1}\right) \neq+1 \rightarrow \\
S\left(R_{t}\right) \neq+1 \\
(\text { Grupo 3) }\end{array}$ & $\begin{array}{c}S\left(R_{t-1}\right)=+1 \rightarrow \\
S\left(R_{t}\right) \neq+1 \\
(\text { Grupo 4) }\end{array}$ \\
\hline Fragilização & Tipologia 1 & Tipologia 4 & Tipologia 7 & Tipologia 10 \\
\hline Fortalecimento & Tipologia 2 & Tipologia 5 & Tipologia 8 & Tipologia 12 \\
\hline Não transição & Tipologia 3 & Tipologia 6 & Tipologia 9 & Tipologia 12 \\
\hline
\end{tabular}

14 Deve-se recordar que o sinal de Rt foi calculado, para fins de computação dos resultados do modelo, a partir da condição (R) da seção 3 . 
Em primeiro lugar, de acordo com o visto na seção 3, espera-se que a informação acerca do sinal assumido por Rt seja suficiente para, com um baixo nível de erro, determinar a postura financeira de uma unidade. Em segundo lugar, espera-se que a alteração do sinal de $R_{t}$ de não positivo (positivo) para positivo (não positivo) ocorrasimultaneamente com a fragilização (fortalecimento) financeira (o) da unidade. Essas duas diretrizes dão base aos seguintes critérios:

A. o indicador a ser calculado - para mensurar a adequação dos resultados ao princípio que com isso busca-se verificar (o formulado na seção 3) é a probabilidade frequentista de ocorrência de uma dada transição, fixada a possibilidade de alteração do valor do sinal de $R_{t}$. P.ex., $P$ (fragilização| alteração do sinal $R_{t}$ de não positivo para positivo $)=\#$ Tipologial $/$ (\#Tipologial +\#Tipologia2 +\#Tipologia3), em que "\#" indica o número de casos de ocorrência da tipologia.

B. Será denotado por $\mathrm{P}\left(\mathrm{T}_{\mathrm{i}}\right)=\#$ Tipologia $_{\mathrm{i}} /\left(\right.$ \#Tipologia $\mathrm{i}_{\mathrm{i}}$ +\#Tipologia $\mathrm{T}_{\mathrm{j}}$ +\#Tipologia $\mathrm{T}_{\mathrm{k}}$ ), a probabilidade da ocorrência da tipologia $i$, em que "j" e " $k$ " são as tipologias que se referem à mesma alteração de sinal que foi observada para "i" (i, j e k, formam, portanto, um mesmo grupo de tipologias). Isso posto, é intuitivo que a verificação do princípio de coincidência entre postura e sinal de $\mathrm{R}_{\mathrm{t}}$ pressupõe a seguinte hierarquia de magnitudes:

$$
\begin{aligned}
& \text { Grupo 1: } P\left(T_{1}\right)>P\left(T_{2}\right) \text { e } P\left(T_{1}\right)>P\left(T_{3}\right) \\
& \text { Grupo 2: } P\left(T_{6}\right)>P\left(T_{4}\right) \text { e } P\left(T_{6}\right)>P\left(T_{5}\right) \\
& \text { Grupo 3: } P\left(T_{9}\right)>P\left(T_{7}\right) \text { e } P\left(T_{9}\right)>P\left(T_{8}\right) \\
& \text { Grupo 4: } P\left(T_{11}\right)>P\left(T_{12}\right) \text { e } P\left(T_{11}\right)>P\left(T_{10}\right)
\end{aligned}
$$

A Tabela 4 abaixo apresenta o resultado gerado ao longo de 30 experimentos de 4.439 iterações cada um. ${ }^{15}$ Como se vê, as evidências apontam que a transição entre posturas hedge e não-hedge e a alteração simultânea do sinal de $\mathrm{R}_{\mathrm{t}}$ ocorrem nos sentidos esperados, de acordo com o formulado na seção 3. Esse resultado é consistente ao longo dos 30 experimentos realizados, como indicado pelo coeficiente de dispersão, o qual foi inferior a 1 , caracterizando a obtenção de um desvio-padrão para os valores reportados, para uma dada probabilidade, inferior à média, e isso para todas as probabilidades computadas. Apesar de $\mathrm{P}(4)$ e $\mathrm{P}(10)$ registrarem um valor superior a 1 para tal indicador, como se vê, isso se deve à presença de um valor outlier (marcado, em cada um dos casos, com o sinal “*”).

15 Os experimentos realizados nesta subseção (4.3.2) não coincidem com aqueles dos quais se retirou os resultados examinados no teste estático (seção 4.3.1). 
Verificar se o aumento da proporção de unidades com uma dada postura coincide com o aumento da proporção de unidades com sinal de $R_{t}$ previsto pelo princípio ora sob exame (vide seção 3), é outro "teste dinâmico" interessante.

Tal teste pode ser visto como uma maneira de explicar períodos de alta (ou de baixa) do grau da fragilidade da economia simulada, se esta for medida pela proporção de unidades não-hedge. ${ }^{16}$ Se os resultados apontarem êxito, será possível dizer que o grau de fragilidade da economia aumenta com a proporção de unidades cujo sinal de $\mathrm{R}_{\mathrm{t}}$ é positivo, e diminui com a queda desta última proporção.

Calculou-se, então, a porcentagem do número de períodos em que a proporção de unidades não-hedge variou na mesma direção que a proporção de unidades com valor positivo para $R_{t}$.

Formalmente, trata-se do indicador:

$\left.\mathrm{f}_{\mathrm{t}^{\prime}} \equiv \sum_{t=2}^{N}\left\{t^{\prime} \in(2, \ldots, N): S\left[\Delta f\left(N H_{t}\right)\right)\right]=S\left[\Delta f\left(S P_{t}\right)\right]\right\} / N$, em que $\mathrm{S}[\Delta \mathrm{f}(\mathrm{NH})] \equiv$ sinal da variação, entre t-l e t, da proporção de unidades não-hedge, $\mathrm{S}[\Delta \mathrm{f}(\mathrm{SP})] \equiv$ sinal da variação, entre $t-1$ e $t$, da proporção de unidades com sinal positivo para $R_{t}$ e $N \equiv$ número de iterações em cada experimento (4.439, conforme já observado).

16 "The stability of an economy's financial structure depends upon the mix of financial postures. For any given regime of financial institutions and government interventions the greater the weight of hedge financing in the economy the greater the stability of the economy whereas and increasing weight of speculative and Ponzi financing indicates an increasing susceptibility to the economy to financial instability (MINSKY, 1982)." A proporção de unidades não-hedge é, portanto, uma medida para o grau de fragilidade financeira (ou instabilidade, na terminologia do excerto), que encontra fundamentação nos escritos de Minsky. Quanto a isso é preciso observar que se trata de uma medida peculiar, já que o "peso" das posturas financeiras é dado pelo número de unidades que as assumem. 
Tabela 4 - Probabilidades de Ocorrência das Tipologias Definidas na Tabela 3, ao longo de 30 Experimentos.

\begin{tabular}{|c|c|c|c|c|c|c|c|c|c|c|c|c|}
\hline \multirow{2}{*}{$E$} & \multicolumn{3}{|c|}{ Grupo 1} & \multicolumn{3}{|c|}{ Grupo 2} & \multicolumn{3}{|c|}{ Grupo 3} & \multicolumn{3}{|c|}{ Grupo 4} \\
\hline & $P\left(T_{1}\right)$ & $\mathrm{P}\left(\mathrm{T}_{2}\right)$ & $\mathrm{P}\left(\mathrm{T}_{3}\right)$ & $\mathrm{P}\left(\mathrm{T}_{4}\right)$ & $\mathrm{P}\left(\mathrm{T}_{5}\right)$ & $P\left(T_{6}\right)$ & $P\left(T_{7}\right)$ & $P\left(T_{8}\right)$ & $P\left(T_{9}\right)$ & $P\left(T_{10}\right)$ & $P\left(T_{11}\right)$ & $P\left(T_{12}\right)$ \\
\hline 1 & $99,9 \%$ & $x$ & $0,1 \%$ & $1,4 \%$ & $x$ & $98,6 \%$ & $x$ & $0,2 \%$ & $99,7 \%$ & $0,4 \%$ & $88,1 \%$ & $1,5 \%$ \\
\hline 2 & $99,9 \%$ & $x$ & $0,1 \%$ & $2,6 \%$ & $x$ & 9 & $x$ & $0,2 \%$ & $99,8 \%$ & $0,1 \%$ & $5,0 \%$ & $130 \%$ \\
\hline 3 & $99,6 \%$ & $x$ & $0,4 \%$ & $0,2 \%$ & $2,0 \%$ & $99,7 \%$ & $x$ & $0,3 \%$ & $99,7 \%$ & $0,5 \%$ & $\%$ & $13,4 \%$ \\
\hline 4 & $99,9 \%$ & $x$ & $0,1 \%$ & $0,9 \%$ & $x$ & $99,1 \%$ & $x$ & $0,3 \%$ & $99,7 \%$ & $0,2 \%$ & $0,2 \%$ & $9,6 \%$ \\
\hline 5 & $100,0 \%$ & $x$ & $x$ & $x$ & $x$ & $100,0 \%$ & $x$ & $0,2 \%$ & $99,8 \%$ & $0,5 \%$ & , $\%$ & $12,3 \%$ \\
\hline 6 & $99,6 \%$ & $x$ & $0,4 \%$ & $0,6 \%$ & $x$ & $99,4 \%$ & $x$ & $0,4 \%$ & $99,6 \%$ & $0,4 \%$ & , $\%$ & $13,8 \%$ \\
\hline 7 & $99,6 \%$ & $x$ & $x$ & $4,9 \%$ & $x$ & $95,1 \%$ & $x$ & $0,4 \%$ & $99,6 \%$ & $0,2 \%$ &, $8 \%$ & $15,0 \%$ \\
\hline 8 & $99,9 \%$ & $x$ & $0,1 \%$ & $2,0 \%$ & $x$ & $98,0 \%$ & $x$ & $0,3 \%$ & $99,7 \%$ & $0,3 \%$ & $2 \%$ & $14,6 \%$ \\
\hline 9 & $99,9 \%$ & $x$ & $0,1 \%$ & $3,5 \%$ & $x$ & $96,5 \%$ & $x$ & $0,2 \%$ & $99,8 \%$ & $0,3 \%$ & $4 \%$ & $12,3 \%$ \\
\hline 10 & $100,0 \%$ & $x$ & $x$ & $25,0 \%$ * & $x$ & $75,0 \%$ & $x$ & $0,3 \%$ & $99,7 \%$ & $0,7 \%$ & $0 \%$ & $17,3 \%$ \\
\hline 11 & $100,0 \%$ & $x$ & $0,6 \%$ & $0,4 \%$ & $x$ & $99,6 \%$ & $x$ & $0,2 \%$ & $99,8 \%$ & $0,1 \%$ &, $5 \%$ & $14,4 \%$ \\
\hline 12 & $99,4 \%$ & $x$ & $0,2 \%$ & $x$ & $x$ & $100,0 \%$ & $x$ & $0,4 \%$ & $99,5 \%$ & $1,2 \%$ & $3,7 \%$ & $15,1 \%$ \\
\hline 13 & $99,8 \%$ & $x$ & $x$ & $x$ & $x$ & $100,0 \%$ & $x$ & $0,2 \%$ & $99,8 \%$ & $0,1 \%$ & $8 \%$ & $11,0 \%$ \\
\hline 14 & $100,0 \%$ & $x$ & $x$ & $x$ & $x$ & $100,0 \%$ & $X$ & $0,4 \%$ & $99,6 \%$ & $0,1 \%$ &, $8 \%$ & $14,1 \%$ \\
\hline 15 & $100,0 \%$ & $x$ & $x$ & $1,0 \%$ & $x$ & $99,0 \%$ & $x$ & $0,3 \%$ & $99,7 \%$ & $0,1 \%$ &, $8 \%$ & $15,0 \%$ \\
\hline 16 & $99,6 \%$ & $x$ & $x$ & $x$ & $x$ & $100,0 \%$ & $x$ & $0,2 \%$ & $99,8 \%$ & $0,2 \%$ &, $2 \%$ & $12,7 \%$ \\
\hline 17 & $99,9 \%$ & $x$ & $0,4 \%$ & $1,8 \%$ & $x$ & $98,2 \%$ & $x$ & $0,4 \%$ & $99,5 \%$ & $0,5 \%$ & $3 \%$ & $14,2 \%$ \\
\hline 18 & $99,9 \%$ & $x$ & $0,1 \%$ & $0,2 \%$ & $x$ & $98,1 \%$ & $x$ & $0,6 \%$ & $99,3 \%$ & $0,3 \%$ & $3,9 \%$ & $15,8 \%$ \\
\hline 19 & $99,6 \%$ & $x$ & $0,1 \%$ & $0,4 \%$ & $x$ & $99,6 \%$ & $x$ & $0,3 \%$ & $99,7 \%$ & $0,1 \%$ & $86,8 \%$ & $13,1 \%$ \\
\hline 20 & $99,9 \%$ & $x$ & $0,4 \%$ & $2,3 \%$ & $x$ & $99,7 \%$ & $x$ & $0,3 \%$ & $99,6 \%$ & $0,1 \%$ & $84,9 \%$ & $15,0 \%$ \\
\hline 21 & $99,8 \%$ & $x$ & $0,1 \%$ & $0,4 \%$ & $x$ & $99,6 \%$ & $x$ & $0,3 \%$ & $99,7 \%$ & $0,2 \%$ & $86,1 \%$ & $13,8 \%$ \\
\hline 22 & $99,7 \%$ & $x$ & $0,2 \%$ & $x$ & $x$ & $100,0 \%$ & $x$ & $0,2 \%$ & $99,8 \%$ & $0,2 \%$ & $85,2 \%$ & $14,6 \%$ \\
\hline 23 & $99,8 \%$ & $x$ & $0,3 \%$ & $x$ & $x$ & $100,0 \%$ & $x$ & $0,5 \%$ & $99,5 \%$ & $0,4 \%$ & $\%$ & $14,5 \%$ \\
\hline 24 & $100,0 \%$ & $X$ & $X$ & $3,0 \%$ & $x$ & $97,0 \%$ & $x$ & $0,3 \%$ & $99,6 \%$ & $0,1 \%$ & $85,6 \%$ & $14,3 \%$ \\
\hline 25 & $99,8 \%$ & $X$ & $0,2 \%$ & $x$ & $x$ & $100,0 \%$ & $x$ & $0,4 \%$ & $99,6 \%$ & $0,9 \%$ & $85,7 \%$ & $13,4 \%$ \\
\hline 26 & $100,0 \%$ & $x$ & $x$ & $x$ & $x$ & $100,0 \%$ & $x$ & $0,5 \%$ & $99,5 \%$ & $1,9 \%^{*}$ & $81,1 \%$ & $16,9 \%$ \\
\hline 27 & $99,6 \%$ & $x$ & $0,4 \%$ & $0,4 \%$ & $x$ & $99,6 \%$ & $x$ & $0,2 \%$ & $99,8 \%$ & $0,8 \%$ & $87,3 \%$ & $11,9 \%$ \\
\hline 28 & $100,0 \%$ & $x$ & $x$ & $x$ & $x$ & $100,0 \%$ & $x$ & $0,4 \%$ & $99,6 \%$ & $0,2 \%$ & $86,7 \%$ & $13,1 \%$ \\
\hline 29 & $99,9 \%$ & $x$ & $0,1 \%$ & $0,5 \%$ & $x$ & $99,5 \%$ & $x$ & $0,2 \%$ & $99,8 \%$ & $0,2 \%$ & $88,9 \%$ & $11,0 \%$ \\
\hline 30 & $99,6 \%$ & $x$ & $0,4 \%$ & $0,7 \%$ & $x$ & $99,3 \%$ & $x$ & $0,3 \%$ & $99,7 \%$ & $0,1 \%$ & $84,9 \%$ & $15,0 \%$ \\
\hline$C D$ & $0,2 \%$ & & $64,4 \%$ & $207,9 \%$ & & $4,6 \%$ & $x$ & $34,3 \%$ & $0,1 \%$ & $104,0 \%$ & $2,2 \%$ & $12,5 \%$ \\
\hline
\end{tabular}

$\mathrm{E}=$ número do experimento, $\mathrm{CD}=$ coeficiente de dispersão. Para as probabilidades $\mathrm{P}(\mathrm{T} 4)$ e $\mathrm{P}(\mathrm{T} 10)$, a eliminação dos valores outliers marcados com o sinal * é suficiente para gerar um coeficiente de dispersão inferior a 1. "X" indica probabilidades que assumiram valor nulo. 
O resultado para os mesmos 10 primeiros experimentos da sequência de 30 experimentos relacionados na tabela 4 acima é reportado a seguir.

Tabela 5 - Valores do Indicador " $f_{t}$ " ao longo dos 30 Experimentos Realizados.

\begin{tabular}{cc}
\hline Experimento & $\mathrm{ft}^{\prime}$ \\
\hline 1 & $97,50 \%$ \\
2 & $98,20 \%$ \\
3 & $97,50 \%$ \\
4 & $98,30 \%$ \\
5 & $98,00 \%$ \\
6 & $96,90 \%$ \\
7 & $97,10 \%$ \\
8 & $97,20 \%$ \\
9 & $98,20 \%$ \\
10 & $96,60 \%$ \\
$\ldots$ & $97,70 \%$ \\
Coeficiente de Dispersão & $0,60 \%$ \\
\hline
\end{tabular}

O coeficiente de dispersão foi calculado a partir dos resultados dos 30 experimentos.

Conforme indica a magnitude assumida por $\mathrm{f}_{\mathrm{t}^{\prime}}$, e o coeficiente de dispersão calculado com base em tal magnitude, consistentemente a fragilização (fortalecimento) da economia ocorre com o aumento (diminuição) do número de unidades que possuem um $R_{t}$ de sinal positivo (não positivo).

\section{Conclusão}

A noção de que o financiamento interno é a variável fundamental para a determinação do grau de estabilidade financeira de uma unidade, proposta por Minsky (1982), foi explorada no presente artigo. Tentou-se chegar às causas últimas, no âmbito das transações por produtos entre firmas, da capacidade de uma unidade para financiar internamente suas operações, concebendo-se, portanto, essa capacidade como resultado de interações mantidas entre empresas capitalistas.

O modelo proposto e estudado no presente artigo permitiu formular princípios de determinação da capacidade de uma unidade para financiar suas operações, cujos fundamentos repousam sobre três variáveis: a proporção do valor do produto correspondente ao custo de produção $(\theta)$, a proporção do valor da produção realizado 
$(\alpha)$ e a sensibilidade do investimento desejado ao lucro esperado $(\gamma)$. Cabe enumerar os principais resultados alcançados.

(i.a) As unidades para as quais as magnitudes de $\alpha, \gamma$ e $\theta$ condicionam uma capacidade plena para financiar internamente o investimento desejado (aquelas que apresentam $\mathrm{R}_{\mathrm{t}}$ não positivo), podem ser classificadas como hedge com erro inferior a $5 \%$ dos casos e;

(i.b) as unidades para as quais as magnitudes de $\alpha, \gamma$ e $\theta$ condicionam a necessidade de financiar externamente (ao menos em parte) o investimento desejado (aquelas que apresentam $R_{t}$ positivo), podem ser classificadas como não-hedge, sem qualquer erro;

(ii) Há correspondência consistente entre a alteração da postura de uma unidade e a alteração do sinal de $R_{t}$ prevista pelos valores idiossincráticos de $\gamma$ e $\theta$, e pelos valores assumidos por $\alpha$ nos períodos entre os quais as alterações referidas se deram;

(iii) A proporção de unidades não-hedge aumenta, pari passu, com a proporção de unidades com sinal positivo para $\mathrm{R}_{\mathrm{t}}$.

Em uma economia hipotética composta por um "lado real" e um "lado financeiro", pôde-se demonstrar que o conjunto informacional específico ao primeiro é suficiente para determinar se uma unidade é capaz de financiar internamente não apenas o investimento produtivo que deseja implementar um passo à frente, mas também o débito contraído com o "lado financeiro", com uma margem de erro desprezível. A contração de financiamento externo, e todos os dados referentes à mesma, podem ser ignorados enquanto determinantes da postura financeira de uma empresa capitalista, à pena de uma perda de precisão analítica estatisticamente ignorável.

Torna-se patente um possível desdobramento de natureza empírica do estudo aqui empreendido. A comprovação da relação entre as variáveis "taxa de realização", "proporção do valor do produto referente ao custo de produção (intimamente relacionado com o mark-up)" e "sensibilidade do investimento ao lucro esperado", de um lado, e a necessidade de financiamento externo (cujo grau é classificado em categorias denominadas "posturas financeiras"), de outro, anuncia-se como horizonte a ser explorado a partir de dados referentes a economias reais. 


\section{Referências}

AXELROD, R. \& TESFATSION, L. A (2009) Guide for Newcomerstoagent-basedmodeling in the Social Sciences Versão eletrônica disponível em http://www. econ.iastate.edu/tesfatsi/abmread.htm

BATTISTON, S., Delli Gatti, D., Gallegati, M., Greenwald, B., Stiglitz, J. E. (2007) Credit chains and bankruptcy propagation in production networks - Journal of Economic Dynamics \& Control 31 (2007) 2061-2084.

CASTI, J. L. (1992) Reality rules: picturing the world in mathematics New York: Wiley.

EPSTEIN, J. M. \& AXTELL, R. Growing artificial societies - social science from the bottom up Brookings Institution Press \&The MIT Press, 1996.

FAZZARI, F., Ferri, P., Greenberg, E. (2008) Cash flow, investment, and KeynesMinsky cycles Journal of Economic Behavior \& Organization vol. 65 (3-4), páginas 555-572.

FOLEY, D. K. MICHL,T .R.- Growth and distribution - Cambridge, Mass. Harvard University Press, 1999.

FOLEY, D. K.(1986) - Liquidity-profit rate cycles in a capitalist economy - Journal of Economic Behavior and Organization 8, 363-376. North-Holland, 1987.

FOLEY,D.K.(2003) - Financial fragility in developing economies - In Dutt, A. K. \&Ros, J. (eds) Development Economics and Structuralist Macroeconomics, Aldershot: Edgard Elgar.

GAlleGATI, D., Giulioni, G., Kichiji, N. Complex Dynamics and Financial Fragility in an Agent Based Model Advances in Complex Systems (ACS), World Scientific Publishing Co. Pte. Ltd., vol. 6(03), páginas 267-282, 2003.

KEYNES, J. M. (1936) (1973) - The General Theory of employment, interest and money The collected writings of John Maynard Keynes. Ed. by D. Moggridge, v.VII. London: Macmillan.

LIMA, G. T. \& FREITAS, G. G.- Debt Financing and Emergent Dynamics of a Financial Fitness Landscape - Anais do XXXV Encontro Nacional de Economia [Proceedings of the 35th Brazilian Economics Meeting], ANPEC, 2007.

LIMA, G. T. - Em busca do tempo perdido: a recuperação pós-keynesiana da economia do emprego de Keynes [Dissertação de Mestrado] EAESP/GV-SP 1992.

MEIRELLES, A. J. A \& LIMA, G. T. - Debt, financial fragility, and economic growth: a Post-Keynesian macromodel - Journal of Post Keynesian Economics, vol. 29 (1), páginas 93-113, 2006.

MINSKY, H. P. - John Maynard Keynes New York: Columbia University Press, 1975.

MINSKY, H. P. - Can it happen again? New York: M.E.Sharpe, 1982. 
PASINETTI, L. L. - The Principle of Effective Demand - In Harcourt,C.C. \&Riach.P.A.(eds):A "Second Edition" of the General Theory, Vol.1.Londres: Routledge, 1973.

PRADO, E. F. S. Microeconomia reducionista e microeconomia sistêmica Revista Nova economia, vol.16 no.2. Belo Horizonte May/Aug, 2006.

RUSSO, A., Delli Gatti, D. e Gallegati, M. Technological Innovation, Financial Fragility and Complex Dynamics Discussion Papers 2004/31, Dipartimento di Scienze Economiche (DSE), University of Pisa, Pisa, Italy, 2004.

TAYLOR, L. \& O'CONNELL, S. A. A Minsky Crisis The Quarterly Journal of Economics, Vol. 100, páginas.871-885, 1985.

WOLFRAM, S. - A new kind of science - Champaign, IL : Wolfram Media, 2002. 